\title{
A short Mindfulness retreat can improve biological markers of stress and inflammation
}

This is a pre print version of the following article:

Original:

Gardi, C., Fazia, T., Stringa, B., Giommi, F. (2022). A short Mindfulness retreat can improve biological markers of stress and inflammation. PSYCHONEUROENDOCRINOLOGY, 135

[10.1016/j.psyneuen.2021.105579].

Availability:

This version is availablehttp://hdl.handle.net/11365/1170906

since 2021-11-29T11:49:53Z

Published:

DOI:10.1016/j.psyneuen.2021.105579

Terms of use:

Open Access

The terms and conditions for the reuse of this version of the manuscript are specified in the publishing policy. Works made available under a Creative Commons license can be used according to the terms and conditions of said license.

For all terms of use and more information see the publisher's website.

(Article begins on next page) 


\section{Journal Pre-proof}

A short Mindfulness retreat can improve biological markers of stress and inflammation

Gardi Concetta, Fazia Teresa, Stringa Blerta, Giommi Fabio

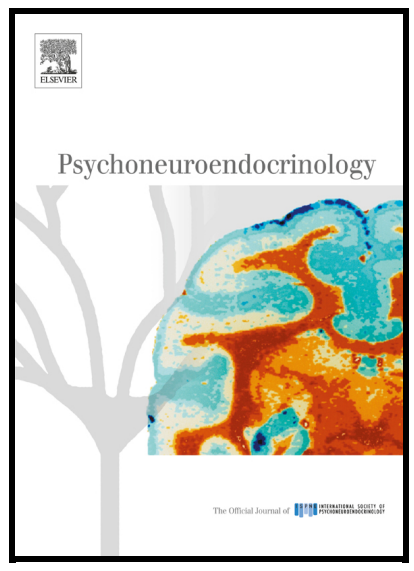

PII: $\quad$ S0306-4530(21)00453-4

DOI: $\quad$ https://doi.org/10.1016/j.psyneuen.2021.105579

Reference: PNEC105579

To appear in: Psychoneuroendocrinology

Received date: 5 May 2021

Revised date: 29 October 2021

Accepted date: 29 October 2021

Please cite this article as: Gardi Concetta, Fazia Teresa, Stringa Blerta and Giommi Fabio, A short Mindfulness retreat can improve biological markers of stress and inflammation, Psychoneuroendocrinology, (2021) doi:https://doi.org/10.1016/j.psyneuen.2021.105579

This is a PDF file of an article that has undergone enhancements after acceptance, such as the addition of a cover page and metadata, and formatting for readability, but it is not yet the definitive version of record. This version will undergo additional copyediting, typesetting and review before it is published in its final form, but we are providing this version to give early visibility of the article. Please note that, during the production process, errors may be discovered which could affect the content, and all legal disclaimers that apply to the journal pertain.

(C) 2021 Published by Elsevier. 


\section{A short Mindfulness retreat can improve biological markers of stress and inflammation}

\section{$\underline{\text { Gardi Concetta }^{1}}$, Fazia Teresa ${ }^{2}$, Stringa Blerta ${ }^{1,3}$, Giommi Fabio $^{4}$}

${ }^{1}$ Department of Molecular and Developmental Medicine, University of Siena, Italy. email: concetta.gardi@unisi.it

${ }^{2}$ Department of Brain and Behavioral Science, Medical and Genomic Statistics Unit, University of Pavia, Italy. teresa.fazia01@ateneopv.it

${ }^{3}$ Present address: Department of Developmental Biology, Washington University in St. Louis, School of Medicine, St. Louis, MO, United States. email: blertastringa@gmail.com

${ }^{4}$ NOUS-School of Specialization (PsyD) in Cognitive and Mindfulness-oriented Psychotherapy, Milano, Italy. AIM-Associazione Italiana per la Mindfulness. fabiomario.giommi@gmail.com

\section{Corresponding author:}

Concetta Gardi, Ph.D.

Department of Molecular and Developmental Medicine

University of Siena, via A. Moro, I-53100 Siena - Italy

Tel. +39-0577-234002

E-mail: concetta.gardi@unisi.it

\section{Highlights}

- A 3-day intensive Mindfulness practice improves biomarkers of stress and inflammation

- Significant reduction in IL-6 and IL-8 and increase in IL-10 levels were found

- Retreat participants showed significant reduction in stress and anxiety levels

- Significant correlation between cortisol values and both anxiety and stress scores. 


\section{Abstract}

Objective: Mindfulness practice, a form of meditation, has shown benefit for psychological and physical health. In this study, we investigated the effect of an intensive period of Mindfulness practice on some biological mediators of stress and inflammation during a 3-day residential retreat.

Methods: A total of 95 healthy individuals (aged 18-67) were recruited and randomized to a Mindfulness retreat arm or an active control arm. Before (t0) and after (t1) the intervention, all the participants were assessed for salivary cortisol levels and for a panel of pro- and anti-inflammatory cytokines measured in saliva. Psychometric measures on stress, anxiety and awareness were carried out using PSS, STAI-Y and MAAS questionnaires, respectively.

Results: As to the within-group differences, we observed a statistically significant decrease in perceived stress $(\beta=-8.85, p<0.0001)$, and anxiety scores $(\beta=-12.39, p<0.0001)$, while awareness increased $(\beta=15.26$, $p<0.0001)$ between t0 to t1 in retreat participants. In the mindfulness intervention group, we also observed a statistically significant reduction in the levels of pro-inflammatory cytokines IL-6 ( $\beta=-0.94 \mathrm{p}=0.001)$ and IL$8(\beta=-176.40, p<0.0001)$, and an increase in anti-inflammatory IL-10 $(\beta=0.89 p<0.0001)$ levels at the end of the retreat. At $\mathrm{t} 1$ we observed a highly significant correlation between cortisol levels and both anxiety $(\mathrm{r}=0.56, \mathrm{p}<0.0001)$ and perceived stress $(\mathrm{r}=0.92, \mathrm{p}<0.0001)$ scores.

Conclusions: Mindfulness retreat participants showed a significant reduction in perceived stress and anxiety levels, as well as an improved balance of some key mediators of inflammatory states. Our data provide evidence that a mindfulness retreat may be effective in improving physical and mental health. Future studies with larger numbers of subjects and follow-up periods may examine mindfulness practice as a nonpharmacological alternative to promote stress reduction and overall health and wellbeing.

Keywords (max 6): cortisol, cytokines, inflammation, Mindfulness, retreat, salivary biomarkers 


\section{Introduction}

A growing body of evidence suggests that Mindfulness meditation may have positive psychological and health effects in both clinical and nonclinical populations (Brown and Ryan, 2003; Grossman et al., 2004; Gu et al., 2015; Pace et al., 2009). Mindfulness Based Programs (MBPs) have been successfully used in patients with chronic conditions to reduce stress and regulate emotions (Grossman et al., 2004) and mood disorders, such as anxiety (Wong et al., 2016) and depression (Kuyken et al., 2015; Piet and Hougaard, 2011).

Evidence emerging from neuroscience research demonstrates that Mindfulness practice can modulate brain neuroplasticity, influencing the structure and function of brain regions involved in the control of attention, regulation of emotion and self-awareness (Santarnecchi et al., 2014, 2021; Tang et al., 2009, 2015). However, the biological mechanisms underlying the effectiveness of Mindfulness are not yet fully known.

Among the biological markers potentially affected by Mindfulness, cortisol secretion is considered a reliable indicator of hypothalamic pituitary adrenal (HPA) axis activity and its levels are generally sensitive to MBPs (Matousek et al., 2010). Also, Mindfulness practice may positively enhance biological functioning through the regulation of inflammatory pathways (Bower and Irwin, 2016). Chronic inflammation plays an important pathogenetic role in many diseases such as asthma, rheumatoid arthritis, diabetes, obesity and Alzheimer's, just to name a few (Slavich, 2015; Weintraub, 2012). Activation of the cell-mediated response and the increased release of inflammatory mediators also contribute to the onset of depressive symptoms, anxiety, fatigue and neurocognitive disorders (Kim et al., 2016; A. H. Miller et al., 2009; Walsh et al., 2016). Chronic exposure to a stressful agent causes a dysregulation of the HPA axis and glucocorticoid-resistance (Cohen et al., 2012; Slavich and Irwin, 2014). Stress can induce a systemic and chronic state of "low-grade inflammation", with increased levels of circulating inflammatory biomarkers such as C-reactive protein (PCR), interleukin 6 (IL-6) and interferon-gamma (INF- $\gamma$ ) (Kiecolt-Glaser et al., 2003; Rohleder, 2012; Steptoe et al., 2007; Szabo et al., 2020).

Studies conducted in randomized clinical trials indicate that MBPs can reduce inflammatory cytokines in stressed subjects (Creswell et al., 2016; Malarkey et al., 2013; Rosenkranz et al., 2013) and down-regulate expression of inflammation-related genes (Creswell et al., 2012). However, most of the studies have examined populations with chronic diseases (Lengacher et al., 2019, 2012; Sanada et al., 2020; Walsh et al., 
2016; Witek Janusek et al., 2019) making it difficult to extend these findings also to healthy individuals.

Finally, many studies in this field fail to include an active control group.

It has been reported that meditation retreats are moderately to highly effective in relieving psychological symptoms of stress, anxiety, and depression (Khoury et al., 2017; Kozasa et al., 2015; Montero-Marin et al., 2016) thus improving wellbeing. In addition, it has been reported that after just 5 days of training, the regulation of the autonomic nervous system (decreased heart rate and blood pressure) improves (Tang et al., 2009). Mindfulness practice may impact different pathways, including changes in the immune and endocrine systems. For example, lower salivary cortisol levels and higher salivary IgA levels were reported after a short training (Tang et al., 2007). However, there are few studies (Cahn et al., 2017; Conklin et al., 2018; Jacobs et al., 2013, 2011; Krygier et al., 2013; Wielgosz et al., 2016) devoted to assessing the impact of intensive Mindfulness retreats on biological parameters, especially on inflammation status, in healthy meditators.

Given the key role of inflammation in health and disease (Weintraub, 2012), we investigated the effects of an intensive Mindfulness practice on stress and inflammation during a 3-day residential retreat. Meditation retreats allow subjects to engage in full-time intensive practice, under the guidance of experienced teachers, but also has the 'vacation' effect which alone might reduce biological processes related to stress and cognitive overload. Therefore, to study the effects of Mindfulness independent of the vacation effect we compared retreat participants with an active control vacation group.

\section{Materials and Methods}

\subsection{Participants}

For this study, 129 healthy women and men aged 18-67 were recruited and randomized to Mindfulness retreat arm or a control vacation arm. Eligibility criteria included: age $>18$ years. Exclusion criteria included: specific psychiatric disturbance (i.e., psychosis, mania, Post Traumatic Stress Disorder, substance dependence, including pharmacologically treated depression), immune disease or disorder, acute illness, cancer, treatment with psychotropic agents and anti-inflammatory drugs (corticosteroids and NSAIDs) in the last month, or a smoking habit. Volunteers were tested at the beginning and at the end of a 3day intensive residential Mindfulness retreat. The effect of participation in a 3-day retreat was compared 
with a 3-day residential vacation group. The control vacation group was hosted at the same resort, but they did not take part in any retreat activities. The study was in agreement with the Helsinki Declaration. Ethical approval was obtained from the local Research Ethics Committee and informed written consent was obtained from all participants. There was no financial incentive offered to participants in either the cost of participating in the retreat or other compensation.

\subsection{Study Procedures}

\subsubsection{Baseline Assessment}

All study participants underwent an identical set of assessments, which included completing study questionnaires and saliva sampling. Participants received an overview of the study, a packet of questionnaires and 2 Salivette tubes for saliva sampling (pre- and post-). Participants gave saliva between 5:00 and 6:00 am and were asked to abstain from caffeine, exercise, and alcohol/drugs at least 12 hours prior to the sampling.

\subsubsection{Description of the Retreat Intervention}

Retreat participants were instructed in Mindfulness meditation, a style of Vipassana practice stemming from the Buddhist tradition. The Mindfulness meditation retreat was guided by two teachers with decades of meditation experience. Both are formally recognized as Roshi (recognized teacher) in a Zen lineage. One teacher has several years of experience as a senior teacher and teacher trainer as a faculty member at the Center For Mindfulness (CFM) founded by Jon Kabat-Zinn at the University of Massachusetts.

The daily schedule included alternating periods ( $45 \mathrm{~min})$ of sitting and walking meditation, for about $10 \mathrm{~h}$ per day, along with free rest time and regular meal times. During sitting meditation, practitioners were asked to focus their attention on their breath and notice any bodily sensations. They were invited to observe their thoughts, sensations and feelings with awareness, kindness and equanimity. During walking meditation, practitioners were instructed to bring attention to the soles of their feet, being aware of the alternating patterns of contact and release, and notice all the different sensations in their feet and the rest of the body. 
The retreat was held in "noble silence", meaning participants refrained from verbal and written communication, as well as eye contact, except during periodic meetings with teachers.

\subsubsection{Active Control (vacation) group}

The control participants followed a schedule similar to retreat participants in terms of wake up, breakfast, lunch, and dinner times. In the morning and the afternoon they were able to choose between a number of leisure options, alone or with others: walking in nature, stretching, resting, reading and conversation with others. They were invited to do what they would normally do on a vacation, emphasizing participation in these activities in a restful way rather than a mindful way. They were asked not to engage in more exercise than they would in their normal lifestyle and to refrain from consumption of more than one alcoholic drink per day.

\subsubsection{Post-treatment Assessment}

The last day of retreat participants completed assessment measures equivalent to those collected during the baseline session.

\subsection{Psychometric Scales}

Psychometric questionnaires included the Perceived Stress Scale (PSS; (Cohen et al., 1983)), the State Anxiety Inventory (STAI-Y form; (Vigneau and Cormier, 2008)), and the Mindful Attention Awareness Scale (MAAS; (Brown and Jones, 2013)).

2.3.1. Perceived Stress Scale (PSS). This is a scaled 10-item questionnaire designed to assess the degree to which situations in a subject's life are perceived as stressful. Each item was rated by patients on a scale ranging from 0 (never) to 4 (very often). Higher scores indicate greater levels of stress.

\subsubsection{State Anxiety Inventory (STAI) - Form Y. This is a self-report questionnaire for measuring anxiety in} adults. The STAI is composed of a total of 20 self-report items related to state anxiety which is defined as the "intensity of the anxiety emotion in this moment". Participants have to indicate how frequently they have the experience shown in each item on a scale ranging from 0 (never) to 4 (very often). 
2.3.3. Mindful Attention Awareness Scale (MAAS). This is a self-report questionnaire used to evaluate the Mindfulness construct of "presence or absence of attention and awareness in the present moment" (Brown and Ryan, 2003). It consists of 15 items that can assess the individual differences in frequency of mindful states and produces a unique major score of Mindfulness. Participants have to indicate how frequently they have the experience shown in each item with a score from 1 to 6 on a Likert scale: 1 (almost always) to 6 (almost never). All items were recoded so that a higher mean score indicates higher mindful attention.

\subsection{Biological evaluation}

\subsubsection{Saliva sampling}

Saliva was collected with the use of Salivettes ${ }^{\circledR}$ (Sarstedt-Nuembrecht, Germany) 30 min after waking up on the day of enrolment and at the end of the 3-day period. Written and verbal instructions were given to participants prior to the procedure. Participants were asked to abstain from caffeine, alcohol, and exercise for 12 hours prior to saliva sample collection. To collect saliva, participants rinsed their mouths with bottled water for 30 seconds, waited $10 \mathrm{~min}$, then removed a swab from Salivette tube and chewed it for about 1 minute to stimulate salivation. The swab was returned to the Salivette tube and immediately stored at $-20^{\circ} \mathrm{C}$ before being transferred to $-80^{\circ} \mathrm{C}$ until the assay was performed.

\subsubsection{Biological assays}

Saliva samples were thawed and then centrifuged at $1000 \mathrm{x} g$ for $1 \mathrm{~min}$ Clear saliva was recovered and used for biological assays. A number of key biomarkers of stress and inflammation were evaluated pre and post retreat on saliva samples. a) Cortisol was assayed using standard enzyme-linked immunoassay procedures (R\&D Systems, Inc., Abingdon, UK). Samples were assayed in duplicate and averaged. Lower limit of detection was $0.07 \mathrm{ng} / \mathrm{ml}$; intra and inter-assay variation had coefficients of covariance at less than $10 \%$. b) Salivary concentrations of cytokines (IL-2, IL-4, IL-6, IL-8, IL-10, IFN- $\gamma$, TNF- $\alpha$ and GM-CSF) were measured according to manufacturer specifications using the Bio-Plex Pro Assays (Bio-Rad Laboratories, Segrate, MI, Italy). Bio-Plex Pro Assays are immunoassays formatted on magnetic beads that utilize principles similar to those of a sandwich ELISA. Capture antibodies against the biomarker of interest are covalently coupled to the beads. A biotinylated detection antibody creates the sandwich complex, and the 
final detection complex is formed by the addition of a streptavidin-phycoerythrin (SA-PE) conjugate, where PE serves as the fluorescent reporter. Reactions are read using a Luminex-based reader. All assays were performed in duplicate to maximize reliability.

\subsection{Statistical Analysis}

Differences between groups at baseline were analyzed using chi-squared test for categorical variable, t-test or Wilcoxon rank-sum test for continuous variables as appropriate.

For each outcome, a nonparametric Wilcoxon signed ranks test was first used to assess the differences between the measurements at $\mathrm{t} 0$ and $\mathrm{t} 1(\mathrm{t} 1-\mathrm{t} 0)$. Then to evaluate pre $(\mathrm{t} 0)$ - post $(\mathrm{t} 1)$ changes between the two groups, accounting for repeated measures, each outcome was analyzed using linear mixed model effect (lme R package) (Pinheiro and Bates, 2000) with group (i.e. control and Mindfulness), time (i.e., t0 and t1) and their interaction (time*group) as fixed effects. Interaction occurs when the effect of one variable depends on the value of another variable; so, in our application, to find a statistically significant interaction term means that there is an effect of time (post-pre) on the outcome which is different in the two groups. In case of statistically significant interaction, we tested the main simple effects, estimating the effect of time separately in each group (within-group pre-post differences). A random intercept for each subject was added in the linear mixed models to account for intra-subject correlation produced by the two repeated measurements (at 0 and $\mathrm{t} 1$ ) carried out on the same subjects (90 subjects $\times 2$ measurements $=180$ observations but only 90 of them independent). P-values $<0.05$ on 2 -sided test is considered as statistically significant. All models were adjusted for sex and age. Benjamini-Hochberg correction, fixing the false discovery rate (FDR) at alpha $<0.05$, was used to account for multiple comparison. Pearson's pairwise partial correlations ( $r$ ), adjusted for sex and age, and the corresponding p-values were also calculated to investigate the relationship between cortisol and IL-6, IL-8, IL-10, PSS, and STAI-Y at t0 and at $\mathrm{t} 1$ in the two groups, both globally and separately. Data are presented as mean \pm Standard Deviation (SD) and all the analysis were performed using R 3.4.2 software (R Development Core Team, 2017).

\section{Results}

\subsection{Participant flow}


For this study 129 women and men were assessed for eligibility and 34 were excluded because they did not meet inclusion criteria $(n=29)$ or declined to participate $(n=5)$. Consequently, a total of $95(73.6 \%)$ were eligible and were randomly allocated to the intervention group $(n=48)$ and to the control vacation group $(n=47)$. The participants' flow chart is shown in Figure 1.

Two people from the intervention group and 3 from the control group were excluded from the analysis due to poor quality of biological samples provided or to failure to deliver saliva sample at $\mathrm{t} 1$ (post).

\subsection{Baseline data}

We analyzed samples from 90 subjects (40 males and 50 females, Age $=46.58 \pm 10.76$ years) randomly allocated to the Mindfulness or control groups. Table 1 reports baseline characteristics of the samples analyzed within each group. The mean age of participants randomized in the Mindfulness and control groups was 46.35 and 46.82, respectively. Female participants were in majority in both groups. However, no significant difference in the number of male and female participants between groups was found $(\mathrm{p}=0.81)$.

The descriptive statistics (mean $\pm \mathrm{SD}$ ) for each outcome variable collected both at $\mathrm{t} 0$ and $\mathrm{t} 1$ in the two groups are reported in Table 2 and the variables' means and their 95\% CI at the two times are plotted in Figure 2. No detectable amounts of other tested cytokines (IL-2, IL-4, IFN- $\gamma$, TNF- $\alpha$ and GM-CSF) were observed in saliva samples from either group. There were no statistically significant differences between the two groups at baseline in the studied variables.

\subsection{Retreat intervention effect}

Firstly, nonparametric Wilcoxon signed ranks test indicates that the difference between the measurements at t0 and $\mathrm{t} 1$ in retreat participants is statistically significant in all the analyzed endpoints: PSS ( $p<0.0001)$, STAI-Y $(p<0.0001)$, MAAS $(p<0.0001)$, cortisol $(p<0.0001)$, IL-6 $(p=0.0002)$, IL-8 $(p<0.0001)$ and IL-10 (p<0.0001).

For the evaluation of pre- and post- treatment changes, results of the linear mixed models are reported in Table 3 and show a different effect of time (post-pre) in the two groups on each outcome 
analyzed being the interaction term (time* group) significant. There was not a significant main effect of gender and age on the variables analyzed.

After testing for the presence of a statistically significant interaction, we also ran a simple effect analysis. This allowed us to stratify the data according to the groups and testing the effect of time separately within each group. After multiple testing correction, this latter analysis showed that PSS scores significantly decreased over time in both the Mindfulness $(\beta=-8.85[95 \% \mathrm{CI}-10.63 ;-7.07] p<0.0001)$ and in the control $(\beta=-2.52[95 \% \mathrm{CI}-3.83 ;-1.22] p=0.002)$ groups. STAI-Y $(\beta=-1.98[95 \% \mathrm{CI}-4.19 ; 0.23] p=0.11)$, MAAS $(\beta=1.70[95 \% \mathrm{CI}-0.19 ; 3.60] p=0.11)$, cortisol level $(\beta=-0.22[95 \% \mathrm{CI}-0.40 ;-0.04] p=0.07)$, and IL-10 level ( $\beta=0.08$ [95\% CI $0.001 ; 0.17] p=0.11)$ did not significantly change over time in the control group. On the other hand, in the mindfulness group we observed a highly significant decrease of STAI-Y scores $(\beta=-12.39$ [95\%CI -14.39; -10.39] $p<0.0001)$ and cortisol level $(\beta=-1.24$ [95\%CI $-1.46 ;-1.02] p<0.0001)$, and a highly significant increase of MAAS scores $(\beta=15.26[95 \%$ CI $12.09 ; 18.43] p<0.0001)$ and IL-10 levels $(\beta=0.89$ [95\%CI 0.75;1.04] $p<0.0001$ ). Finally, IL-6 and IL-8 levels did not show statistically significant change over time in the control group $(\beta=-0.11$ [95\%CI $-0.41 ; 0.19] p=0.55$ and $\beta=7.85$ [95\% CI $-53.97 ; 69.67] p=0.80$, respectively) but were significantly decreased in the mindfulness group ( $\beta=-0.94$ [95\%CI $-1.49 ;-0.40]$ $\mathrm{p}=0.001$ and $\beta=-176.40[95 \% \mathrm{CI}-242.79 ;-110.01] p<0.0001$, respectively).

\subsection{Correlations between cortisol and IL-6, IL-8, IL-10, PSS and STAI-Y}

Considering the two groups globally, Pearson's pairwise partial correlations showed that at t0, cortisol values have a high statistical positive correlation with IL-6 levels ( $r=0.40 \mathrm{p}=1.6 \mathrm{e}-04)$, STAI-Y scores $(\mathrm{r}=0.63, \mathrm{p}<0.0001)$ and PSS scores $(\mathrm{r}=0.97, \mathrm{p}<0.0001)$, but have only a mild statistical positive correlation with IL-8 levels $(r=0.25 \mathrm{p}=0.02)$. No correlation was observed between cortisol and IL-10 $(r=-0.18 \mathrm{p}=0.09)$. Similar results were also found at $\mathrm{t}$, which show a high statistical positive correlation between cortisol values and IL-8 levels $(r=0.45 \mathrm{p}<0.0001)$, STAI-Y scores $(r=0.64, p<0.0001)$ and PSS scores $(r=0.95$, $\mathrm{p}<0.001)$ and a mild significant correlation with IL-6 levels $(\mathrm{r}=0.27 \mathrm{p}=0.01)$. In relation to cortisol and IL10, at $\mathrm{t} 1 \mathrm{we}$ observed a statistically significant negative correlation $(\mathrm{r}=-0.42, \mathrm{p}<0.0001)$. 
If we consider the two groups separately, within the Mindfulness group at t0 we did not observe a significant correlation between cortisol values and IL-6 ( $r=0.24 \mathrm{p}=0.11)$, IL-8 ( $r=0.18 \mathrm{p}=0.23)$ and IL-10 $(\mathrm{r}=0.003, \mathrm{p}=0.98)$ levels. Instead, we observed a significant correlation between cortisol values and both STAI-Y $(r=0.64, p<0.0001)$ and PSS $(r=0.98, p<0.0001)$ scores. Similar results were also obtained at $t 1$, where there was not a significant correlation between cortisol values and IL-6 ( $r=0.05 p=0.73)$ and IL-10 $(\mathrm{r}=-0.24, \mathrm{p}=0.11)$ and only a mildly significant correlation between cortisol values and IL- 8 levels $(\mathrm{r}=0.30 \mathrm{p}=$ 0.04) were observed. At t1, similar to findings at t0, we observed a highly significant correlation between cortisol values and both STAI-Y $(r=0.56, \mathrm{p}<0.0001)$ and PSS $(\mathrm{r}=0.92, \mathrm{p}<0.0001)$ scores.

When analyzing the control group, at t0 we observed a highly significant correlation between cortisol values and IL-6 levels $(r=0.70 p<0.0001)$, STAI-Y ( $r=0.63, p<0.0001)$, PSS score $(r=0.97, p<0.0001)$, IL-8 levels $(\mathrm{r}=0.38 \mathrm{p}=0.01)$ and IL-10 levels $(\mathrm{r}=-0.38, \mathrm{p}=0.02)$. Similar results were also obtained at $\mathrm{t}$, showing a significant correlation between cortisol values and IL-6 levels $(r=0.49 \mathrm{p}=0.001)$, IL-8 levels $(r=0.44$, $\mathrm{p}=0.003)$, PSS scores $(\mathrm{r}=0.94, \mathrm{p}<0.0001)$ and STAI-Y scores $(\mathrm{r}=0.48 \mathrm{p}=0.001)$. No significant correlation was observed at $\mathrm{t} 1$ between cortisol values and IL-10 $(\mathrm{r}=-0.23, \mathrm{p}=0.14)$.

To visualize the relationship between cortisol and PSS, which shows a highly significant positive partial correlation, in Figure 3 we have plotted the residuals of the linear regression between PSS as outcome and age and sex as predictors (y-axes) and the residuals of the linear regression between cortisol as outcome and age and sex as predictors ( $\mathrm{x}$-axes).

\section{Discussion}

Extensive evidence in the literature demonstrates that Mindfulness practice can reduce psychological symptomatology (e.g., decreases in perceived stress, anxiety and depression) and supports the notion that Mindfulness-based programs may be beneficial for individuals coping with a wide variety of clinical and non-clinical problems (Grossman et al., 2004; Gu et al., 2015). However, some concerns have been raised about the subjectivity of these self-reports which may not reflect bodily states in a valid or reliable manner.

The present study examines whether a brief intensive Mindfulness retreat could reduce self-reported distress and related salivary inflammatory markers in healthy individuals. As predicted, the obtained results 
highlight the positive impact of Mindfulness practice on biomarkers of stress and inflammation in promoting psychological wellbeing through decrease in perceived stress and anxiety levels and an increase in awareness.

While beneficial effects of a Mindfulness retreat on combined psychological symptoms (including anxiety, depression and stress), as well as increases in awareness have been described (Cahn et al., 2017; Jacobs et al., 2011; Khoury et al., 2017; Montero-Marin et al., 2016), not all researchers have reported beneficial effects of participation in a Mindfulness retreat on the physiological pathways that are modulated by stress.

Cortisol is the main stress hormone and measurement of free cortisol levels within the 60 min after awakening in the morning is considered a stable and reliable biological marker of adrenocortical activity (Matousek et al., 2010). In our study, we found decreases in self-reported distress questionnaires (PSS), regardless of whether subjects were in the intensive Mindfulness retreat or in the vacation group. In the Mindfulness group, decrease in perceived stress was associated to a highly significant decrease of cortisol levels which did not significantly change over time in the control group. The similarities between the groups in subjective stress perception may be attributed to the beneficial effects of short-term relaxation typical of a vacation.

However, our study design allowed us to evaluate the specific effects of a Mindfulness retreat independent of the vacation effect. In fact, only participants in the 3-day retreat also self-reported statistically significant decreases in anxiety as well as significant increases in awareness. Our data are in agreement with previous studies showing that participation in retreats is associated with decrease in self-reported anxiety (Cahn et al., 2017). Anxiety is a common neurobehavioral correlate of a variety of stressors. It is known that stress responses are differentially influenced by the individual perception of the stressor and the perceived ability to cope with it. One potential explanation for how MBPs reduce anxiety is that these interventions reduce avoidance of negative affect. Mindfulness practice increases capacity for emotional regulation and awareness of inner and outer experiences. This helps develop an attitude of acceptance of these experiences as they are, without reacting to them or judging them negatively. It has been reported that Mindfulness practice may reduce negative dimensions of psychological distress and promote emotional regulation by enhancing the ability of cognitive reappraisal (Garland et al., 2015). Mindfulness seems to recruit brain 
circuits exerting an emotion regulation onto the amygdala, one of the brain structures that is known as highly relevant for emotional processing (Kral et al., 2018). Studies have shown that Mindfulness practice improves executive brain functioning and increases activation of prefrontal cortical areas (PFC) - specifically dorsolateral (DLPFC), ventrolateral (VLPFC), dorsomedial (DMPFC) - and insula during the expectation, but not the perception of negative stimuli (Brown and Jones, 2013; Opialla et al., 2015). Interestingly, once activated, mindful processing may no longer require activation of prefrontal areas. In fact, in experienced meditators exposed to unpleasant or painful stimuli, sensory processing regions of the brain showed greater activation, while activation of prefrontal regions appeared to decrease, suggesting a lack of effortful regulation (e.g., stimulus reappraisal) (Gard et al., 2012).

In the past few decades, psychoneuroimmunology studies have demonstrated the interplay between the central nervous system (CNS) and the immune system, and how thoughts and emotions may affect immune function. Psychological stress may alter immune function by activating physiological pathways, such as the autonomic nervous system and the HPA axis. Additionally, it has also become apparent that the immune system can influence the CNS, indicating a bidirectional circuit between these two systems. The interaction between these two systems is confirmed by the co-existence of increased levels of cortisol and pro-inflammatory cytokines in psychological disorders such as depression and anxiety (Felger, 2017; Horowitz et al., 2020). Glucocorticoids appear to be crucial in controlling the individual repertoire and magnitude of immune reactions. Various immune cells express glucocorticoid receptors which bind cortisol and interfere with the function of NF-kB, a key player in the regulation of inflammation (Riccardi et al., 2002). In the present study, we observed a highly significant correlation between cortisol levels and both STAI-Y (anxiety) and PSS (perceived stress) scores in the retreat participants.

Of particular interest are the findings related to the effect of the Mindfulness retreat on markers of inflammation. In the Mindfulness group we detected a statistically significant reduction in the levels of two important pro-inflammatory cytokines (IL-6 and IL-8), and a significant increase in the levels of antiinflammatory cytokine IL-10. These changes were not present in the active control group.

Many human and animal studies have shown that physiological pathways involving inflammatory and stress responses likely play an important role in the etiology of anxiety and other psychiatric disorders (O’Donovan et al., 2010; Sominsky et al., 2013). IL-6 is a molecule that plays a key role in organizing 
inflammatory responses and increased levels of this cytokine have been associated with acute and chronic stress levels (Rohleder, 2014). In mice, repeated social defeat stress caused a robust increase in IL-6, which induced a recruitment of pro-inflammatory monocytes to the brain triggering the onset of anxiety-like behavior (Niraula et al., 2019). In line with a hypothesized decrease in inflammatory processes resulting from intensive Mindfulness practices, we found that the pro-inflammatory cytokine IL- 8 was significantly reduced after the retreat. This cytokine shows chemotactic activity and plays a key role in the acute exacerbation of inflammation. In addition to its function in the immune system, IL- 8 also shows neuroprotective properties. Plasma IL-8 positively correlated with perceived stress and with symptoms of anxiety (Memon et al., 2017). The cytokine response to stress also includes Th2-mediated production of IL10, an anti-inflammatory cytokine able to reduce the expression of the Th1-produced pro-inflammatory cytokines. Decreased IL-10 expression was found in the hippocampus of the stressed mice (Labaka et al., 2017). In the present study, we detected a significant increase in the levels of anti-inflammatory cytokine IL10 in the Mindfulness group after retreat. The increase in this cytokine has been hypothesized to be related to enhanced stress resilience. This hypothesis is supported by a study carried out on individuals exposed to urban violence in Brazil. In this study, the more resilient individuals exposed to trauma but not experiencing PTSD showed significantly higher IL-10 levels (Teche et al., 2017).

To the best of our knowledge, this is the first study in which salivary pro- and anti-inflammatory markers from a healthy population have been investigated before and after an intensive Mindfulness retreat. Previous studies have demonstrated the health benefits of a meditation retreat on psychological outcomes, but few also reported the effect on some biological parameters. Cahn et al. (Cahn et al., 2017) have shown that participation in a 3-months yoga-meditation retreat was associated with increases in the plasma levels of brain derived neurotrophic factor (BDNF) and anti-inflammatory cytokine IL-10, and a reduction of proinflammatory cytokine IL-12. Surprisingly, plasma levels of other pro-inflammatory cytokines, including IL6 , and IL-8 were increased after the retreat. To explain this discrepancy, the authors hypothesize various explanations, including the stress inherent in the intensive 3-month meditation retreat. Conversely, Shields et al. (Shields et al., 2020) found a decreased inflammatory activity (indexed as the ratio of IL-6 to IL-10) from the pre- to the post-retreat assessment in participants of a 3-months meditation retreat. This was significantly associated with better controlled attention, supporting the idea that higher levels of inflammatory activity 
may affect executive function and controlled attention. Cortisol and pro-inflammatory cytokines are both know to affect the hippocampus and cognitive functioning, interacting via central and peripheral mechanisms (Sudheimer et al., 2014).

It is important to emphasize that, unlike the above reported studies, biological assays for the present study were carried out using saliva. Compared to plasma, saliva has multiple advantages, including noninvasiveness and ease of sample collection which can be performed independently by the participant. This enables a safer and easier sample collection in a retreat setting. Another advantage is that this kind of sampling requires minimal active compliance on the part of the subject being studied, without pain or stress. Despite evidence that salivary levels of cytokines do not always correlate with plasma concentrations, they can be measured, and they have increased significantly in response to stress across multiple studies (for a review see (Slavish et al., 2015). MBPs have been found to be effective in reducing salivary cytokines in different clinical setting (Lengacher et al., 2019, 2012; Walsh et al., 2016). However, to the best of our knowledge, studies investigating the effect of an intensive Mindfulness retreat on salivary cytokines are lacking.

Although we cannot discriminate which parts of the retreat affect these beneficial changes, it is likely that they are due to a combination of psychological and behavioral factors that lead to better coping mechanisms, along with regulation of biological pathways that improve our stress response. Both the autonomic nervous system and immune system are widely regarded as systems that cannot be voluntarily influenced. However, some studies (Kox et al., 2012, 2014) demonstrated that these systems can be voluntarily influenced through some practices, such as meditation and breathing techniques. In these studies, voluntary activation of the sympathetic nervous system resulted in epinephrine release and higher plasma levels of the anti-inflammatory cytokine IL-10, which negatively correlated with levels of pro-inflammatory mediators.

Moreover, our hypothesis is that, even in subjects considered healthy, slightly altered levels of inflammatory markers may be present, presumably attributable to the phenomenon of systemic low-grade inflammation. This type of inflammation has to be carefully distinguished from responses to infection or injury and it is much lower in magnitude (Rohleder, 2019). There is evidence that exposure to everyday social stress and certain social, environmental and lifestyle factors can promote systemic low-grade 
inflammation (Miller et al., 2019) (Rohleder, 2019) (Kiecolt-Glaser et al., 2003) (G. E. Miller et al., 2009). At the current state of knowledge, it is not possible to extrapolate what reported for blood parameters to salivary parameters, and changes in salivary cytokines do not necessarily indicate systemic change. This may be considered a limitation of the present study. However, although saliva-based measures do not map well onto systemic measures of inflammation, they may still be strongly predictive of disease and well-being and may have both clinical and research utility. In healthy people, several studies have found associations between salivary levels of cytokines and psychosocial factors (Giletta et al., 2018; Janusek et al., 2017; Saban et al., 2018). Higher levels of some salivary cytokines have been found in adults after social stressor tasks (Chiang et al., 2012; Izawa et al., 2013), socio-cognitive stress (La Fratta et al., 2018) or in response to prolonged stress (Lester et al., 2010). In light of the above reported discussion, we believe that decreases in salivary cytokines observed in our study may be relevant to evaluate the effect of an intensive mindfulness practice. Additional research validating salivary inflammation measures to systemic inflammation and to health is needed.

Another limitation of the study should be taken into account. Previous meditation experience of participants was not screened. Most participants had previous meditation experience at beginner level (1-3 years). However, we have no data about the frequency and continuity of their daily meditation routines. It would have been interesting to compare the experienced meditators with meditation-naïve people, but this was not possible in the present study.

Lastly, the lack of follow-up measures does not allow to determine the long-term effects and the stability over times of the observed changes related to retreat.

\section{Conclusion}

The reported data as a whole support our hypothesis that a Mindfulness retreat could not only improve mental wellbeing by reducing stress and anxiety, but would also impact the inflammatory pathway by reducing some key mediators of inflammatory states. These findings provide suggestive evidence that Mindfulness retreat experiences may deserve increased consideration by researchers as a worthwhile avenue to continue to examine ways to promote stress reduction and overall health and wellbeing. 


\section{Conflict of interest}

All the authors declare that there is no conflict of interest.

\section{Author contributions}

C.G.: Conceptualization, Methodology, Writing - Review \& editing, Project administration, Funding acquisition. T.F.: Formal analysis, Methodology, Supervision. B.S.: Methodology, Laboratory investigation. F.G.: Funding acquisition, Supervision, Review \& editing.

\section{Acknowledgment}

This work was supported by the Fondazione Telecom-TIM (Project «Resilienza») and partially by PSR (Piano di Sostegno alla Ricerca), University of Siena, Siena, Italy. Authors are grateful for the English language editing provided by Lisa Cameli and Eleonora Pellegini.

\section{References}

Bower, J.E., Irwin, M.R., 2016. Mind-body therapies and control of inflammatory biology: A descriptive review. Brain. Behav. Immun. 51, 1-11.

Brown, C.A., Jones, A.K.P., 2013. Psychobiological correlates of improved mental health in patients with musculoskeletal pain after a mindfulness-based pain management program. Clin. J. Pain 29, 233-244.

Brown, K.W., Ryan, R.M., 2003. The Benefits of Being Present: Mindfulness and Its Role in Psychological Well-Being. J. Pers. Soc. Psychol. 84, 822-848. https://doi.org/10.1037/0022-3514.84.4.822

Cahn, B.R., Goodman, M.S., Peterson, C.T., Maturi, R., Mills, P.J., 2017. Yoga, meditation and mind-body health: Increased BDNF, cortisol awakening response, and altered inflammatory marker expression after a 3-month yoga and meditation retreat. Front. Hum. Neurosci. 11, 315. https://doi.org/10.3389/fnhum.2017.00315

Chiang, J.J., Eisenberger, N.I., Seeman, T.E., Taylor, S.E., 2012. Negative and competitive social interactions are related to heightened proinflammatory cytokine activity. Proc. Natl. Acad. Sci. U. S. A. 109, 1878-82. https://doi.org/10.1073/pnas.1120972109

Cohen, S., Janicki-Deverts, D., Doyle, W.J., Miller, G.E., Frank, E., Rabin, B.S., Turner, R.B., 2012. 
Chronic stress, glucocorticoid receptor resistance, inflammation, and disease risk. Proc. Natl. Acad. Sci. U. S. A. 109, 5995-5999. https://doi.org/10.1073/pnas.1118355109

Cohen, S., Kamarck, T., Mermelstein, R., 1983. A global measure of perceived stress. J. Health Soc. Behav. 24, 385-396. https://doi.org/10.2307/2136404

Conklin, Q.A., King, B.G., Zanesco, A.P., Lin, J., Hamidi, A.B., Pokorny, J.J., Álvarez-López, M.J., CosínTomás, M., Huang, C., Kaliman, P., Epel, E.S., Saron, C.D., 2018. Insight meditation and telomere biology: The effects of intensive retreat and the moderating role of personality. Brain. Behav. Immun. 70, 233-245. https://doi.org/10.1016/j.bbi.2018.03.003

Creswell, J.D., Irwin, M.R., Burklund, L.J., Lieberman, M.D., Arevalo, J.M.G., Ma, J., Breen, E.C., Cole, S.W., 2012. Mindfulness-Based Stress Reduction training reduces loneliness and pro-inflammatory gene expression in older adults: A small randomized controlled trial. Brain. Behav. Immun. 26, 10951101. https://doi.org/10.1016/j.bbi.2012.07.006

Creswell, J.D., Taren, A.A., Lindsay, E.K., Greco, C.M., Gianaros, P.J., Fairgrieve, A., Marsland, A.L., Brown, K.W., Way, B.M., Rosen, R.K., Ferris, J.L., 2016. Alterations in resting-state functional connectivity link mindfulness meditation with reduced interleukin-6: A randomized controlled trial. Biol. Psychiatry 80, 53-61. https://doi.org/10.1016/j.biopsych.2016.01.008

Felger, J.C., 2017. Imaging the role of inflammation in mood and anxiety-related disorders. Curr. Neuropharmacol. 16, 533-558. https://doi.org/10.2174/1570159x15666171123201142

Gard, T., Hölzel, B.K., Sack, A.T., Hempel, H., Lazar, S.W., Vaitl, D., Ott, U., 2012. Pain attenuation through mindfulness is associated with decreased cognitive control and increased sensory processing in the brain. Cereb. Cortex 22, 2692-2702. https://doi.org/10.1093/cercor/bhr352

Garland, E.L., Hanley, A., Farb, N.A., Froeliger, B.E., 2015. State Mindfulness During Meditation Predicts Enhanced Cognitive Reappraisal. Mindfulness (N. Y). 6, 234-242. https://doi.org/10.1007/s12671-013$0250-6$

Giletta, M., Slavich, G.M., Rudolph, K.D., Hastings, P.D., Nock, M.K., Prinstein, M.J., 2018. Peer victimization predicts heightened inflammatory reactivity to social stress in cognitively vulnerable adolescents. J. Child Psychol. Psychiatry Allied Discip. 59, 129-139. https://doi.org/10.1111/jcpp.12804 
Grossman, P., Niemann, L., Schmidt, S., Walach, H., 2004. Mindfulness-based stress reduction and health benefits. J. Psychosom. Res. 57, 35-43. https://doi.org/10.1016/S0022-3999(03)00573-7

Gu, J., Strauss, C., Bond, R., Cavanagh, K., 2015. How do mindfulness-based cognitive therapy and mindfulness-based stress reduction improve mental health and wellbeing? A systematic review and meta-analysis of mediation studies. Clin Psychol Rev 37, 1-12. https://doi.org/10.1016/j.cpr.2015.01.006

Horowitz, M.A., Cattaneo, A., Cattane, N., Lopizzo, N., Tojo, L., Bakunina, N., Musaelyan, K., Borsini, A., Zunszain, P.A., Pariante, C.M., 2020. Glucocorticoids prime the inflammatory response of human hippocampal cells through up-regulation of inflammatory pathways. Brain. Behav. Immun. 87, 777794. https://doi.org/10.1016/j.bbi.2020.03.012

Izawa, S., Sugaya, N., Kimura, K., Ogawa, N., Yamada, K.C., Shirotsuki, K., Mikami, I., Hirata, K., Nagano, Y., Nomura, S., 2013. An increase in salivary interleukin-6 level following acute psychosocial stress and its biological correlates in healthy young adults. Biol. Psychol. 94, 249-54. https://doi.org/10.1016/j.biopsycho.2013.06.006

Jacobs, T.L., Epel, E.S., Lin, J., Blackburn, E.H., Wolkowitz, O.M., Bridwell, D.A., Zanesco, A.P., Aichele, S.R., Sahdra, B.K., MacLean, K.A., King, B.G., Shaver, P.R., Rosenberg, E.L., Ferrer, E., Wallace, B.A., Saron, C.D., 2011. Intensive meditation training, immune cell telomerase activity, and psychological mediators. Psychoneuroendocrinology 36, 664-81. https://doi.org/10.1016/j.psyneuen.2010.09.010

Jacobs, T.L., Shaver, P.R., Epel, E.S., Zanesco, A.P., Aichele, S.R., Bridwell, D.A., Rosenberg, E.L., King, B.G., MacLean, K.A., Sahdra, B.K., Kemeny, M.E., Ferrer, E., Wallace, B.A., Saron, C.D., 2013. Selfreported mindfulness and cortisol during a shamatha meditation retreat. Heal. Psychol. 32. https://doi.org/10.1037/a0031362

Janusek, L.W., Tell, D., Gaylord-Harden, N., Mathews, H.L., 2017. Relationship of childhood adversity and neighborhood violence to a proinflammatory phenotype in emerging adult African American men: An epigenetic link. Brain. Behav. Immun. 60, 126-135. https://doi.org/10.1016/j.bbi.2016.10.006

Khoury, B., Knäuper, B., Schlosser, M., Carrière, K., Chiesa, A., 2017. Effectiveness of traditional meditation retreats: A systematic review and meta-analysis. J. Psychosom. Res. 92, 16-25. 
https://doi.org/10.1016/j.jpsychores.2016.11.006

Kiecolt-Glaser, J.K., Preacher, K.J., MacCallum, R.C., Atkinson, C., Malarkey, W.B., Glaser, R., 2003.

Chronic stress and age-related increases in the proinflammatory cytokine IL-6. Proc. Natl. Acad. Sci. U. S. A. https://doi.org/10.1073/pnas.1531903100

Kim, Y.K., Na, K.S., Myint, A.M., Leonard, B.E., 2016. The role of pro-inflammatory cytokines in neuroinflammation, neurogenesis and the neuroendocrine system in major depression. Prog. NeuroPsychopharmacology Biol. Psychiatry. https://doi.org/10.1016/j.pnpbp.2015.06.008

Kox, M., Stoffels, M., Smeekens, S.P., Van Alfen, N., Gomes, M., Eijsvogels, T.M.H., Hopman, M.T.E., Van Der Hoeven, J.G., Netea, M.G., Pickkers, P., 2012. The influence of concentration/meditation on autonomic nervous system activity and the innate immune response: A case study. Psychosom. Med. 74, 489-94. https://doi.org/10.1097/PSY.0b013e3182583c6d

Kox, M., Van Eijk, L.T., Zwaag, J., Van Den Wildenberg, J., Sweep, F.C.G.J., Van Der Hoeven, J.G., Pickkers, P., 2014. Voluntary activation of the sympathetic nervous system and attenuation of the innate immune response in humans. Proc. Natl. Acad. Sci. U. S. A. 111, 7379-7384. https://doi.org/10.1073/pnas.1322174111

Kozasa, E.H., Lacerda, S.S., Menezes, C., Wallace, B.A., Radvany, J., Mello, L.E.A.M., Sato, J.R., 2015. Effects of a 9-Day Shamatha Buddhist Meditation Retreat on Attention, Mindfulness and SelfCompassion in Participants with a Broad Range of Meditation Experience. Mindfulness (N. Y). 6, 1235-1241. https://doi.org/10.1007/s12671-015-0385-8

Kral, T.R.A., Schuyler, B.S., Mumford, J.A., Rosenkranz, M.A., Lutz, A., Davidson, R.J., 2018. Impact of short- and long-term mindfulness meditation training on amygdala reactivity to emotional stimuli. Neuroimage 181, 301-313. https://doi.org/10.1016/j.neuroimage.2018.07.013

Krygier, J.R., Heathers, J.A.J., Shahrestani, S., Abbott, M., Gross, J.J., Kemp, A.H., 2013. Mindfulness meditation, well-being, and heart rate variability: A preliminary investigation into the impact of intensive vipassana meditation. Int. J. Psychophysiol. 89, 305-313. https://doi.org/10.1016/j.ijpsycho.2013.06.017

Kuyken, W., Hayes, R., Barrett, B., Byng, R., Dalgleish, T., Kessler, D., Lewis, G., Watkins, E., Morant, N., Taylor, R.S., Byford, S., 2015. The effectiveness and cost-effectiveness of mindfulness-based cognitive 
therapy compared with maintenance antidepressant treatment in the prevention of depressive relapse/recurrence: Results of a randomised controlled trial (The PREVENT study). Health Technol. Assess. (Rockv). https://doi.org/10.3310/hta19730

La Fratta, I., Tatangelo, R., Campagna, G., Rizzuto, A., Franceschelli, S., Ferrone, A., Patruno, A., Speranza, L., De Lutiis, M.A., Felaco, M., Grilli, A., Pesce, M., 2018. The plasmatic and salivary levels of IL-1 $\beta$, IL-18 and IL-6 are associated to emotional difference during stress in young male. Sci. Rep. 8, 3031. https://doi.org/10.1038/s41598-018-21474-y

Labaka, A., Gómez-Lázaro, E., Vegas, O., Pérez-Tejada, J., Arregi, A., Garmendia, L., 2017. Reduced hippocampal IL-10 expression, altered monoaminergic activity and anxiety and depressive-like behavior in female mice subjected to chronic social instability stress. Behav. Brain Res. 335, 8-18. https://doi.org/10.1016/j.bbr.2017.08.002

Lengacher, C.A., Kip, K.E., Barta, M., Post-White, J., Jacobsen, P.B., Groer, M., Lehman, B., Moscoso, M.S., Kadel, R., Le, N., Loftus, L., Stevens, C.A., Malafa, M.P., Shelton, M.M., 2012. A Pilot Study Evaluating the Effect of Mindfulness-Based Stress Reduction on Psychological Status, Physical Status, Salivary Cortisol, and Interleukin-6 Among Advanced-Stage Cancer Patients and Their Caregivers. J. Holist. Nurs. 30, 170-85. https://doi.org/10.1177/0898010111435949

Lengacher, C.A., Reich, R.R., Paterson, C.L., Shelton, M., Shivers, S., Ramesar, S., Pleasant, M.L., Budhrani-Shani, P., Groer, M., Post-White, J., Johnson-Mallard, V., Kane, B., Cousin, L., Moscoso, M.S., Romershausen, T.A., Park, J.Y., 2019. A Large Randomized Trial: Effects of Mindfulness-Based Stress Reduction (MBSR) for Breast Cancer (BC) Survivors on Salivary Cortisol and IL-6. Biol. Res. Nurs. 21, 39-49. https://doi.org/10.1177/1099800418789777

Lester, S.R., Brown, J.R., Aycock, J.E., Grubbs, S.L., Johnson, R.B., 2010. Use of saliva for assessment of stress and its effect on the immune system prior to gross anatomy practical examinations. Anat. Sci. Educ. 3, 160-7. https://doi.org/10.1002/ase.161

Malarkey, W.B., Jarjoura, D., Klatt, M., 2013. Workplace based mindfulness practice and inflammation: A randomized trial. Brain. Behav. Immun. 27, 145-154. https://doi.org/10.1016/j.bbi.2012.10.009

Matousek, R.H., Dobkin, P.L., Pruessner, J., 2010. Cortisol as a marker for improvement in mindfulnessbased stress reduction. Complement. Ther. Clin. Pract. https://doi.org/10.1016/j.ctcp.2009.06.004 
Memon, A.A., Sundquist, K., Ahmad, A., Wang, X., Hedelius, A., Sundquist, J., 2017. Role of IL-8, CRP and epidermal growth factor in depression and anxiety patients treated with mindfulness-based therapy or cognitive behavioral therapy in primary health care. Psychiatry Res. 254, 311-316. https://doi.org/10.1016/j.psychres.2017.05.012

Miller, A.H., Maletic, V., Raison, C.L., 2009. Inflammation and Its Discontents: The Role of Cytokines in the Pathophysiology of Major Depression. Biol. Psychiatry. https://doi.org/10.1016/j.biopsych.2008.11.029

Miller, E.S., Apple, C.G., Kannan, K.B., Funk, Z.M., Plazas, J.M., Efron, P.A., Mohr, A.M., 2019. Chronic stress induces persistent low-grade inflammation. Am. J. Surg. 218, 677-683. https://doi.org/10.1016/j.amjsurg.2019.07.006

Miller, G.E., Rohleder, N., Cole, S.W., 2009. Chronic interpersonal stress predicts activation of pro- and anti-inflammatory signaling pathways 6 months later. Psychosom. Med. 71, 57-62. https://doi.org/10.1097/PSY.0b013e318190d7de

Montero-Marin, J., Puebla-Guedea, M., Herrera-Mercadal, P., Cebolla, A., Soler, J., Demarzo, M., Vazquez, C., Rodríguez-Bornaetxea, F., García-Campayo, J., 2016. Psychological effects of a 1-month meditation retreat on experienced meditators: The role of non-attachment. Front. Psychol. 7, 1935. https://doi.org/10.3389/fpsyg.2016.01935

Niraula, A., Witcher, K.G., Sheridan, J.F., Godbout, J.P., 2019. Interleukin-6 Induced by Social Stress Promotes a Unique Transcriptional Signature in the Monocytes That Facilitate Anxiety. Biol. Psychiatry 85, 679-689. https://doi.org/10.1016/j.biopsych.2018.09.030

O’Donovan, A., Hughes, B.M., Slavich, G.M., Lynch, L., Cronin, M.T., O’Farrelly, C., Malone, K.M., 2010. Clinical anxiety, cortisol and interleukin-6: Evidence for specificity in emotion-biology relationships. Brain. Behav. Immun. 24, 1074-1077. https://doi.org/10.1016/j.bbi.2010.03.003

Opialla, S., Lutz, J., Scherpiet, S., Hittmeyer, A., Jäncke, L., Rufer, M., Grosse Holtforth, M., Herwig, U., Brühl, A.B., 2015. Neural circuits of emotion regulation: a comparison of mindfulness-based and cognitive reappraisal strategies. Eur. Arch. Psychiatry Clin. Neurosci. 265, 45-55. https://doi.org/10.1007/s00406-014-0510-z

Pace, T.W.W., Negi, L.T., Adame, D.D., Cole, S.P., Sivilli, T.I., Brown, T.D., Issa, M.J., Raison, C.L., 2009. 
Effect of compassion meditation on neuroendocrine, innate immune and behavioral responses to psychosocial stress. Psychoneuroendocrinology. https://doi.org/10.1016/j.psyneuen.2008.08.011

Piet, J., Hougaard, E., 2011. The effect of mindfulness-based cognitive therapy for prevention of relapse in recurrent major depressive disorder: a systematic review and meta-analysis. Clin. Psychol. Rev. 31, 1032-40. https://doi.org/10.1016/j.cpr.2011.05.002

Pinheiro, J.C., Bates, D.M., 2000. Mixed-effects models in S and S-PLUS. Springer.

R Development Core Team, 2017. R: a language and environment for statistical computing. Vienna, Austria R Found. Stat. Comput.

Riccardi, C., Bruscoli, S., Migliorati, G., 2002. Molecular mechanisms of immunomodulatory activity of glucocorticoids. Pharmacol. Res. 45, 361-8. https://doi.org/10.1006/phrs.2002.0969

Rohleder, N., 2019. Stress and inflammation - The need to address the gap in the transition between acute and chronic stress effects. Psychoneuroendocrinology 105, 164-171. https://doi.org/10.1016/j.psyneuen.2019.02.021

Rohleder, N., 2014. Stimulation of systemic low-grade inflammation by psychosocial stress. Psychosom. Med. 76, 181-9. https://doi.org/10.1097/PSY.0000000000000049

Rohleder, N., 2012. Acute and chronic stress induced changes in sensitivity of peripheral inflammatory pathways to the signals of multiple stress systems. Psychoneuroendocrinology 37, 307-316. https://doi.org/10.1016/j.psyneuen.2011.12.015

Rosenkranz, M.A., Davidson, R.J., MacCoon, D.G., Sheridan, J.F., Kalin, N.H., Lutz, A., 2013. A comparison of mindfulness-based stress reduction and an active control in modulation of neurogenic inflammation. Brain. Behav. Immun. 27, 174-184. https://doi.org/10.1016/j.bbi.2012.10.013

Saban, K.L., Mathews, H.L., Bryant, F.B., Tell, D., Joyce, C., DeVon, H.A., Witek Janusek, L., 2018. Perceived discrimination is associated with the inflammatory response to acute laboratory stress in women at risk for cardiovascular disease. Brain. Behav. Immun. 73, 625-632. https://doi.org/10.1016/j.bbi.2018.07.010

Sanada, K., Montero-Marin, J., Barceló-Soler, A., Ikuse, D., Ota, M., Hirata, A., Yoshizawa, A., Hatanaka, R., Valero, M.S., Demarzo, M., Campayo, J.G., Iwanami, A., 2020. Effects of mindfulness-based interventions on biomarkers and low-grade inflammation in patients with psychiatric disorders: A meta- 
analytic review. Int. J. Mol. Sci. 21, 2484. https://doi.org/10.3390/ijms21072484

Santarnecchi, E., D’Arista, S., Egiziano, E., Gardi, C., Petrosino, R., Vatti, G., Reda, M., Rossi, A., 2014. Interaction between neuroanatomical and psychological changes after mindfulness-based training. PLoS One. https://doi.org/10.1371/journal.pone.0108359

Santarnecchi, E., Egiziano, E., D’Arista, S., Gardi, C., Romanella, S.M., Mencarelli, L., Rossi, S., Reda, M., Rossi, A., 2021. Mindfulness-based stress reduction training modulates striatal and cerebellar connectivity. J. Neurosci. Res. https://doi.org/10.1002/jnr.24798

Shields, G.S., Skwara, A.C., King, B.G., Zanesco, A.P., Dhabhar, F.S., Saron, C.D., 2020. Deconstructing the effects of concentration meditation practice on interference control: The roles of controlled attention and inflammatory activity. Brain. Behav. Immun. 89, 256-267. https://doi.org/10.1016/j.bbi.2020.06.034

Slavich, G.M., 2015. Understanding inflammation, its regulation, and relevance for health: A top scientific and public priority. Brain. Behav. Immun. 45, 13-14. https://doi.org/10.1016/j.bbi.2014.10.012

Slavich, G.M., Irwin, M.R., 2014. From stress to inflammation and major depressive disorder: A social signal transduction theory of depression. Psychol. Bull. https://doi.org/10.1037/a0035302

Slavish, D.C., Graham-Engeland, J.E., Smyth, J.M., Engeland, C.G., 2015. Salivary markers of inflammation in response to acute stress. Brain. Behav. Immun. 44, 253-69. https://doi.org/10.1016/j.bbi.2014.08.008

Sominsky, L., Fuller, E.A., Bondarenko, E., Ong, L.K., Averell, L., Nalivaiko, E., Dunkley, P.R., Dickson, P.W., Hodgson, D.M., 2013. Functional Programming of the Autonomic Nervous System by Early Life Immune Exposure: Implications for Anxiety. PLoS One 8, e57700. https://doi.org/10.1371/journal.pone.0057700

Steptoe, A., Hamer, M., Chida, Y., 2007. The effects of acute psychological stress on circulating inflammatory factors in humans: A review and meta-analysis. Brain. Behav. Immun. 21, 901-12. https://doi.org/10.1016/j.bbi.2007.03.011

Sudheimer, K.D., O’Hara, R., Spiegel, D., Powers, B., Kraemer, H.C., Neri, E., Weiner, M., Hardan, A., Hallmayer, J., Dhabhar, F.S., 2014. Cortisol, cytokines, and hippocampal volume interactions in the elderly. Front. Aging Neurosci. 6, 153. https://doi.org/10.3389/fnagi.2014.00153

Szabo, Y.Z., Slavish, D.C., Graham-Engeland, J.E., 2020. The effect of acute stress on salivary markers of 
inflammation: A systematic review and meta-analysis. Brain. Behav. Immun. 88, 887-900. https://doi.org/10.1016/j.bbi.2020.04.078

Tang, Y.-Y., Hölzel, B.K., Posner, M.I., 2015. The neuroscience of mindfulness meditation. Nat. Rev. Neurosci. 16, 213-225. https://doi.org/10.1038/nrn3916

Tang, Y.-Y., Ma, Y., Fan, Y., Feng, H., Wang, J., Feng, S., Lu, Q., Hu, B., Lin, Y., Li, J., Zhang, Y., Wang, Y., Zhou, L., Fan, M., 2009. Central and autonomic nervous system interaction is altered by short-term meditation. Proc. Natl. Acad. Sci. U. S. A. 106, 8865-70. https://doi.org/10.1073/pnas.0904031106

Tang, Y.Y., Ma, Y., Wang, J., Fan, Y., Feng, S., Lu, Q., Yu, Q., Sui, D., Rothbart, M.K., Fan, M., Posner, M.I., 2007. Short-term meditation training improves attention and self-regulation. Proc. Natl. Acad. Sci. U. S. A. 104, 17152-17156. https://doi.org/10.1073/pnas.0707678104

Teche, S.P., Rovaris, D.L., Aguiar, B.W., Hauck, S., Vitola, E.S., Bau, C.H.D., Freitas, L.H., Grevet, E.H., 2017. Resilience to traumatic events related to urban violence and increased IL10 serum levels.

Psychiatry Res. 250, 136-140. https://doi.org/10.1016/j.psychres.2017.01.072

Vigneau, F., Cormier, S., 2008. The factor structure of the state-trait anxiety inventory: An alternative view. J. Pers. Assess. 90, 280-285. https://doi.org/10.1080/00223890701885027

Walsh, E., Eisenlohr-Moul, T., Baer, R., 2016. Brief mindfulness training reduces salivary IL-6 and TNF- $\alpha$ in young women with depressive symptomatology. J. Consult. Clin. Psychol. 84, 887-97. https://doi.org/10.1037/ccp0000122

Weintraub, N.L., 2012. The role of inflammation in health and disease: Translating discovery into novel therapeutic approaches, in: Translational Research. https://doi.org/10.1016/j.trsl.2012.05.002

Wielgosz, J., Schuyler, B.S., Lutz, A., Davidson, R.J., 2016. Long-term mindfulness training is associated with reliable differences in resting respiration rate. Sci. Rep. 6, 27533. https://doi.org/10.1038/srep27533

Witek Janusek, L., Tell, D., Mathews, H.L., 2019. Mindfulness based stress reduction provides psychological benefit and restores immune function of women newly diagnosed with breast cancer: A randomized trial with active control. Brain. Behav. Immun. 80, 358-373. https://doi.org/10.1016/j.bbi.2019.04.012

Wong, S.Y.S., Yip, B.H.K., Mak, W.W.S., Mercer, S., Cheung, E.Y.L., Ling, C.Y.M., Lui, W.W.S., Tang, 
W.K., Lo, H.H.M., Wu, J.C.Y., Lee, T.M.C., Gao, T., Griffiths, S.M., Chan, P.H.S., Ma, H.S.W., 2016.

Mindfulness-based cognitive therapy v. group psychoeducation for people with generalised anxiety

disorder: Randomised controlled trial. Br. J. Psychiatry. https://doi.org/10.1192/bjp.bp.115.166124

\section{LEGEND TO FIGURES}

Figure 1. Flow chart for participants in our study. This includes enrollment, allocation and analysis of participants. Of the 129 people screened, 95 (73.6\%) were eligible and were randomly allocated to groups. After the retreat, 2 from Mindfulness group and 3 from active control group were excluded from the analysis due to failure to deliver saliva sample or poor quality of sample.

Figure 2. Plot of the mean and $95 \%$ CI pre and post treatment for each variable in the two groups. Changes in psychometric measures STAI-Y (anxiety), MAAS (awareness) and PSS (perceived stress), and in biomarker levels of cortisol and cytokines in Mindfulness intervention group and active control group across baseline and 8-week time points. P-value of interaction between time and group is also reported.

Figure 3. Partial correlation, adjusted for sex and age, between cortisol and PSS. The residuals of the linear regression between PSS as outcome and age and sex as predictors are reported in y-axes, while the residuals of the linear regression between cortisol as outcome and age and sex as predictors are reported in xaxes both in all the subjects and separately in the mindfulness and control groups at both time points. 


\section{Enrollment}

Assessed for eligibility $(n=129)$

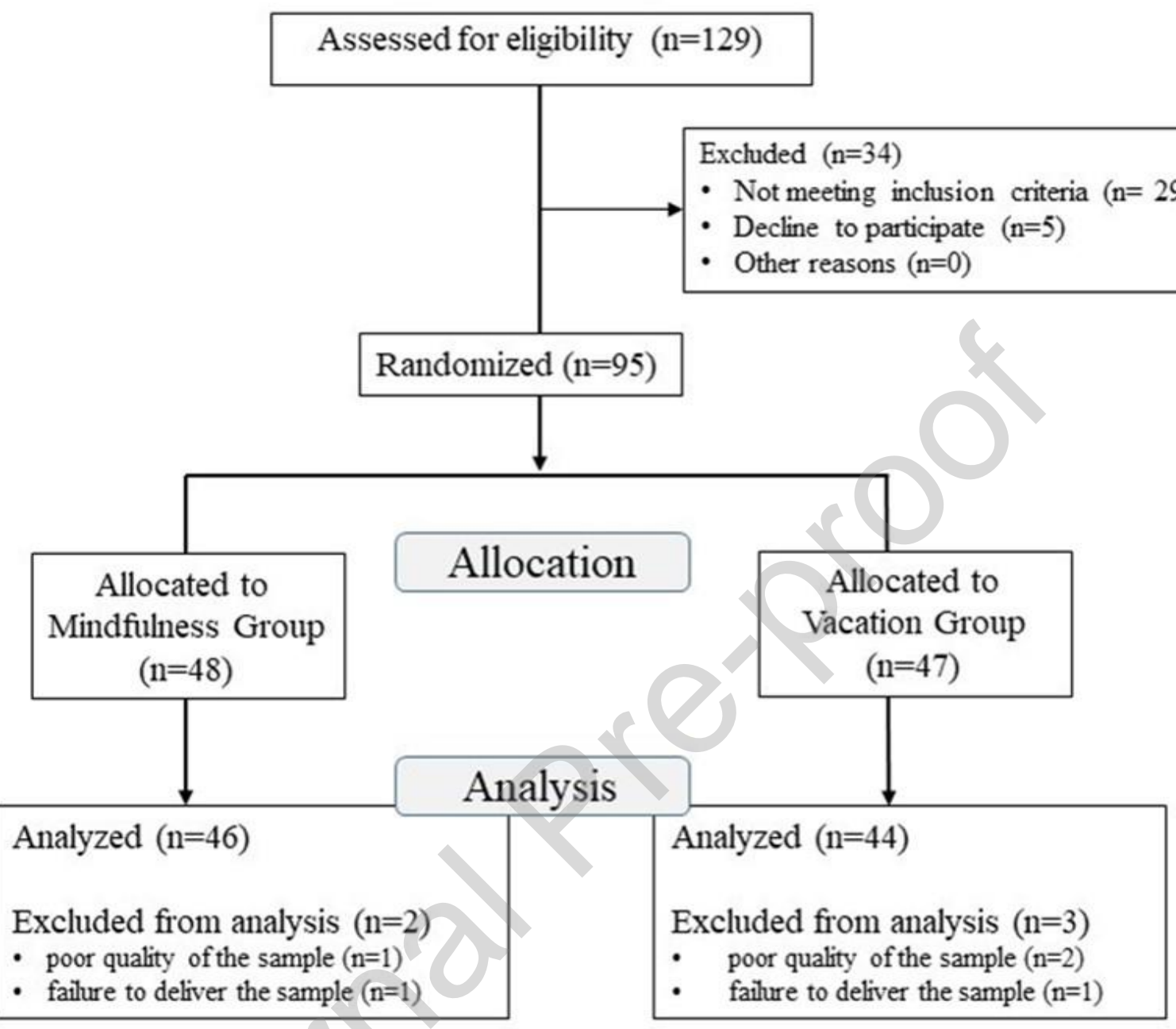

Fig 1 

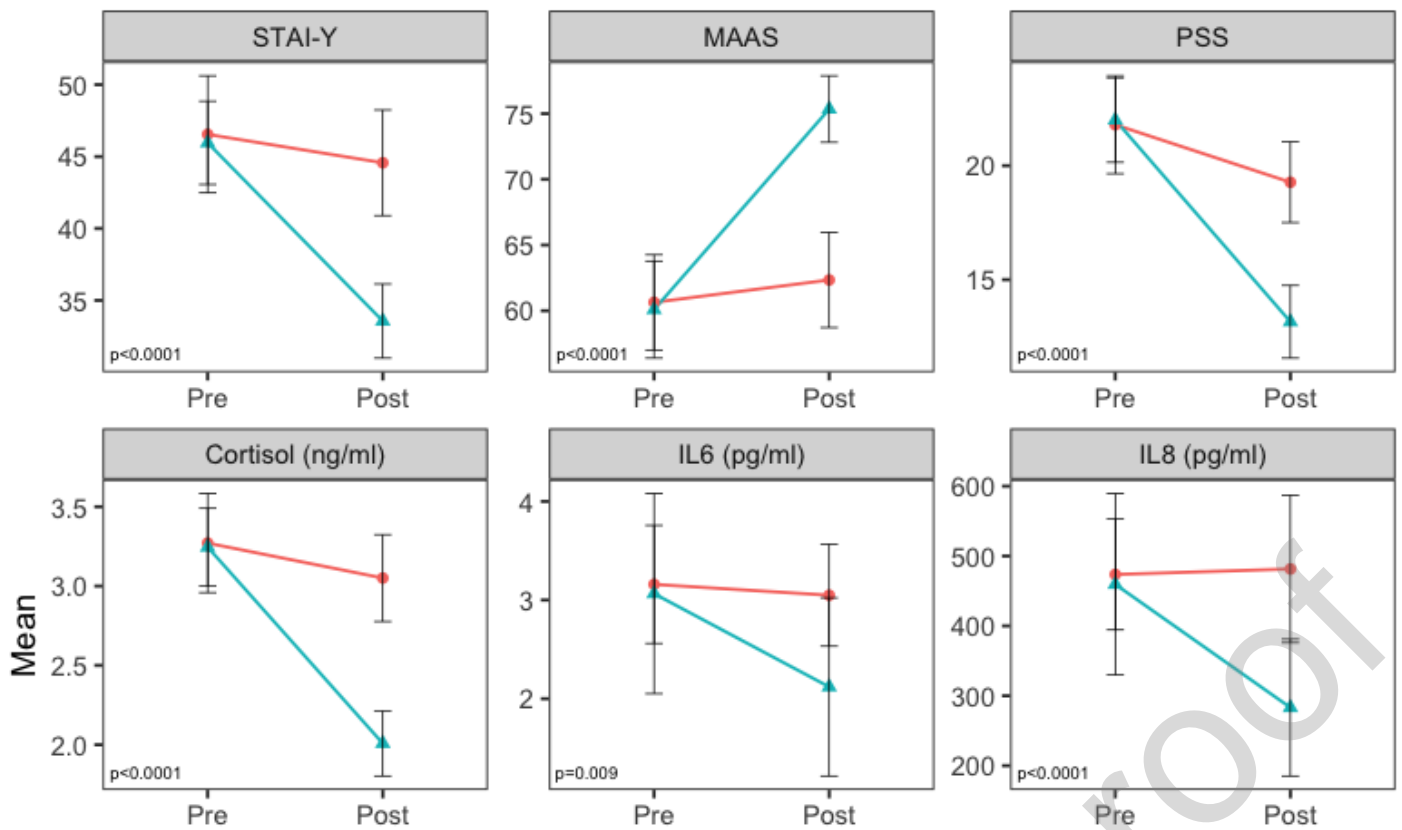

Group

$\rightarrow$ Control

$\simeq$ Meditation

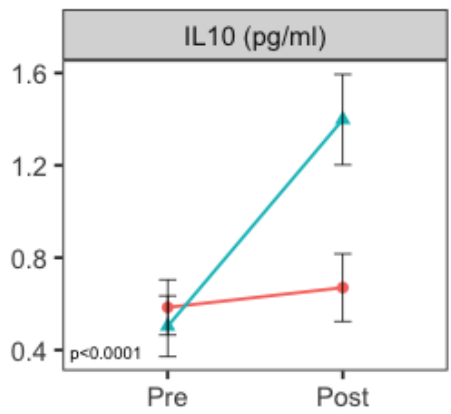

time

Fig 2 

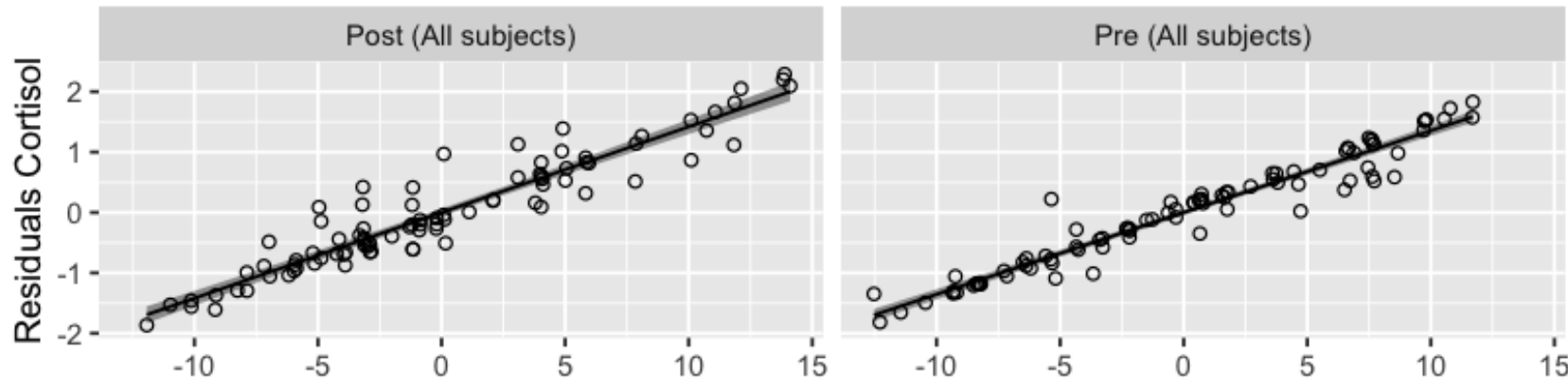

\section{Residuals PSS}
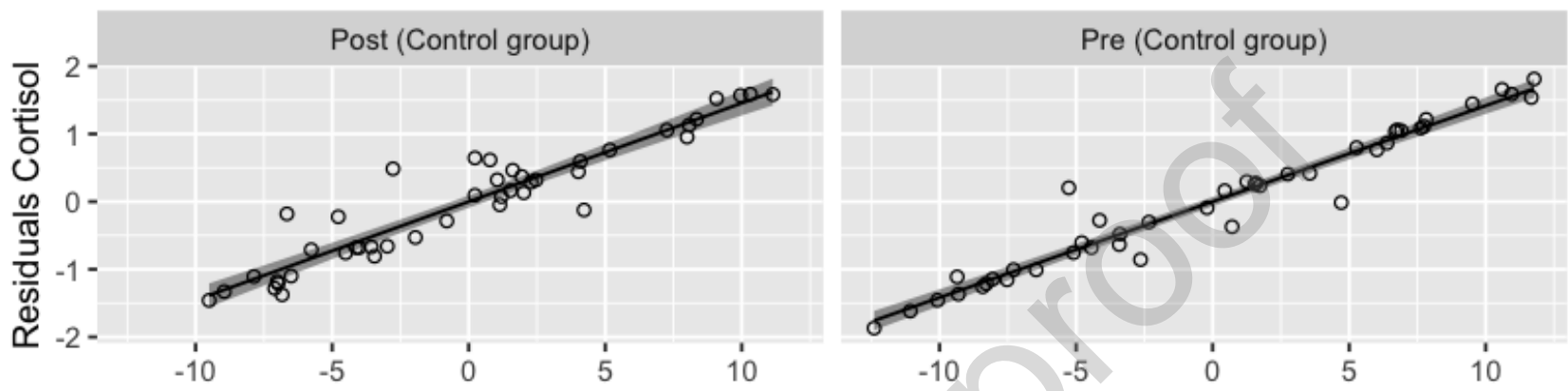

Residuals PSS

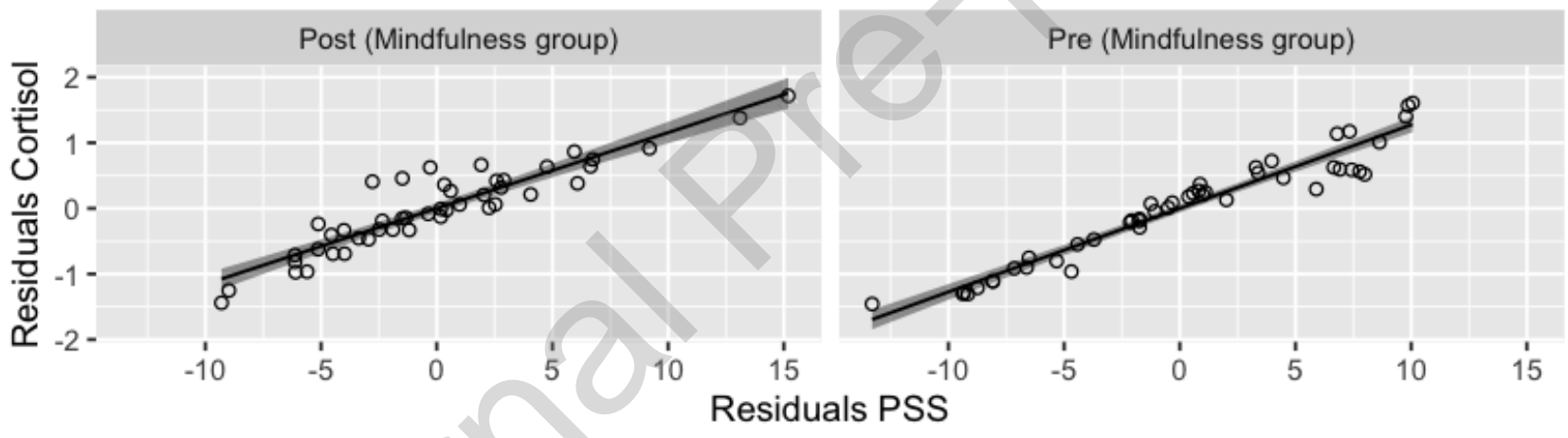

Fig 3

Table 1. Baseline characteristics of the sample stratified by group (i.e. Mindfulness and Control).

\begin{tabular}{llll}
\hline & $\begin{array}{l}\text { Mindfulness } \\
(\mathrm{n}=46)\end{array}$ & $\begin{array}{l}\text { Control } \\
(\mathrm{n}=44)\end{array}$ & p-value \\
\hline Sex & 21 & 19 & 0.98 \\
Male & 25 & 25 & \\
Female & $46.35 \pm 10.11$ & $46.82 \pm 11.51$ & 0.72 \\
Age \pm SD & & & \\
\hline
\end{tabular}


Table 2. Descriptive statistics of the outcome variables at $t 0$ and $t 1$ in the two groups.

\begin{tabular}{|c|c|c|c|c|c|c|c|c|c|}
\hline & \multicolumn{4}{|c|}{ Mindfulness $(\mathrm{N}=46)$} & \multicolumn{5}{|c|}{ Control $(\mathrm{N}=44)$} \\
\hline & $\begin{array}{c}\text { Mean } \pm S D \\
(t 0)\end{array}$ & $\begin{array}{l}\% C V \\
(t 0)\end{array}$ & $\begin{array}{c}\text { Mean } \pm S D \\
(t 1)\end{array}$ & $\begin{array}{l}\% C V \\
(t 1)\end{array}$ & $\begin{array}{c}\text { Mean } \pm S D \\
(t 0)\end{array}$ & $\begin{array}{l}\% C V \\
(t 0)\end{array}$ & $\begin{array}{c}\text { Mean } \pm S D \\
\text { (t1) }\end{array}$ & $\begin{array}{l}\% C V \\
(t 1)\end{array}$ & ${ }^{a} p$-value \\
\hline PSS & $22.00 \pm 6.24$ & 28.38 & $13.15 \pm 5.37$ & 40.80 & $21.80 \pm 7.06$ & 32.83 & $19.27 \pm 5.81$ & 30.16 & 0.88 \\
\hline STAI-Y & $45.96 \pm 9.74$ & 21.19 & $33.56 \pm 8.68$ & 25.85 & $46.54 \pm 13.39$ & 28.76 & $44.57 \pm 12.07$ & 27.09 & 0.81 \\
\hline MAAS & $60.09 \pm 12.45$ & 20.71 & $75.35 \pm 8.53$ & 11.32 & $60.64 \pm 11.91$ & 19.75 & $62.34 \pm 11.92$ & 19.12 & 0.83 \\
\hline IL-6 (pg/ml) & $3.06 \pm 3.41$ & 111.44 & $2.12 \pm 3.04$ & 143.38 & $3.16 \pm 1.97$ & & $3.05 \pm 1.70$ & 55.79 & 0.29 \\
\hline IL-8 (pg/ml) & $459.55 \pm 437.27$ & 95.15 & $283.15 \pm 329.42$ & 116.34 & $473.66 \pm 260.96$ & 55.10 & $481.51 \pm 347.24$ & 72.11 & 0.23 \\
\hline $\begin{array}{l}\text { IL-10 } \\
(\mathrm{pg} / \mathrm{ml})\end{array}$ & $0.50 \pm 0.44$ & 88.34 & $1.40 \pm 0.66$ & 47.21 & $0.58 \pm 0.39$ & 67.54 & $0.67 \pm 0.48$ & 71.76 & 0.08 \\
\hline $\begin{array}{l}\text { Cortisol } \\
\text { (ng/ml) }\end{array}$ & $3.24 \pm 0.82$ & 25.38 & $2.09 \pm 0.69$ & 32 & $3.27 \pm 1.03$ & 31.37 & $3.05 \pm 0.90$ & 29.50 & 0.95 \\
\hline
\end{tabular}


Table 3. Results of the linear mixed model fitted for each endpoint.

\begin{tabular}{|c|c|c|c|c|c|c|}
\hline & $\begin{array}{l}\text { Fixed effect } \\
(\beta)\end{array}$ & $\begin{array}{l}\text { St. } \\
\text { Error }\end{array}$ & 95\% CI & DF & t-value & $\begin{array}{l}\text { p-value } \\
\text { adjusted }\end{array}$ \\
\hline \multicolumn{7}{|l|}{ PSS } \\
\hline Intercept & 22.89 & 2.74 & {$[17.45 ; 28.33]$} & 88 & 8.36 & $<0.0001$ \\
\hline Time & -2.52 & 0.79 & {$[-4.09 ;-0.96]$} & 88 & -3.20 & 0.002 \\
\hline Mindfulness & 0.23 & 1.30 & {$[-2.35 ; 2.82]$} & 86 & 0.18 & 0.86 \\
\hline Time X & -6.32 & 1.10 & {$[-8.52 ;-4.13]$} & 88 & -5.73 & $<0.0001$ \\
\hline \multicolumn{7}{|l|}{ Mindfulness } \\
\hline \multicolumn{7}{|l|}{ STAI-Y } \\
\hline Intercept & 43.56 & 5.15 & {$[33.33 ; 53.80]$} & 88 & 8.46 & $<0.0001$ \\
\hline Time & -1.98 & 1.06 & {$[-4.08 ; 0.12]$} & 88 & -1.87 & 0.06 \\
\hline Mindfulness & -0.49 & 2.34 & {$[-5.15 ; 4.17]$} & 86 & -0.21 & 0.83 \\
\hline Time $X$ & -10.41 & 1.48 & {$[-13.35 ;-7.48]$} & 88 & -7.05 & $<0.0001$ \\
\hline \multicolumn{7}{|l|}{ Mindfulness } \\
\hline \multicolumn{7}{|l|}{ MAAS } \\
\hline Intercept & 67.23 & 5.10 & {$[57.10 ; 77.36]$} & 88 & 13.19 & $<0.0001$ \\
\hline Time & 1.70 & 1.33 & {$[-0.93 ; 4.34]$} & 88 & 1.28 & 0.20 \\
\hline Mindfulness & -0.64 & 2.38 & {$[-5.38 ; 4.10]$} & 86 & -0.27 & 0.79 \\
\hline Time X & 13.56 & 1.85 & {$[9.87 ; 17.24]$} & 88 & 7.31 & $<0.0001$ \\
\hline \multicolumn{7}{|l|}{ Mindfulness } \\
\hline \multicolumn{7}{|l|}{ IL-6 } \\
\hline Intercept & 1.38 & 1.23 & {$[-1.07 ; 3.84]$} & 88 & 1.12 & 0.27 \\
\hline Time & -0.11 & 0.22 & {$[-0.55 ; 0.33]$} & 88 & -0.49 & 0.62 \\
\hline Mindfulness & -0.08 & 0.56 & {$[-1.19 ; 1.02]$} & 86 & -0.15 & 0.88 \\
\hline Time X & -0.83 & 0.31 & {$[-1.45 ;-0.21]$} & 88 & -2.67 & 0.009 \\
\hline \multicolumn{7}{|l|}{ Mindfulness } \\
\hline \multicolumn{7}{|l|}{ IL-8 } \\
\hline Intercept & 472.35 & 164.18 & {$[146.07 ; 798.63]$} & 88 & 2.88 & 0.005 \\
\hline Time & 7.85 & 32.25 & {$[-56.24 ; 71.94]$} & 88 & 0.24 & 0.81 \\
\hline Mindfulness & -15.57 & 74.51 & {$[-163.69 ; 132.54]$} & 86 & -0.21 & 0.83 \\
\hline Time X & -184.25 & 45.11 & {$[-273.89 ;-94.60]$} & 88 & -4.08 & $<0.0001$ \\
\hline \multicolumn{7}{|l|}{ Mindfulness } \\
\hline \multicolumn{7}{|l|}{ IL-10 } \\
\hline Intercept & 0.76 & 0.23 & {$[0.31 ; 1.21]$} & 88 & 3.33 & 0.001 \\
\hline Time & 0.08 & 0.06 & {$[-0.04 ; 0.21]$} & 88 & 1.39 & 0.17 \\
\hline
\end{tabular}




$\begin{array}{lllclll}\text { Mindfulness } & -0.08 & 0.11 & {[-0.29 ; 0.13]} & 86 & -0.76 & 0.45 \\ \text { Time X } & 0.81 & 0.09 & {[0.64 ; 0.98]} & 88 & 9.41 & <\mathbf{0 . 0 0 0 1} \\ \text { Mindfulness } & & & & & & \end{array}$

\section{Cortisol}

Intercept

3.35

0.39

[2.57; 4.13]

88

8.55

$<0.0001$

Time

$-0.22$

0.10

[-0.42; -0.02]

88

$-2.15$

0.03

Mindfulness

$-0.02$

0.18

[-0.39; 0.34]

$-0.11$

0.91

Time X

$-1.02$

0.14

[-1.30; -0.73]

$-7.10$

$<0.0001$

Mindfulness

$\mathrm{DF}=$ degree of freedom; $\mathrm{CI}=$ Confidence Interval

\section{Highlights}

- A 3-day intensive Mindfulness practice improves biomarkers of stress and inflammation

- $\quad$ Significant reduction in IL-6 and IL-8 and increase in IL-10 levels were found

- Retreat participants showed significant reduction in stress and anxiety levels

- $\quad$ Significant correlation between cortisol values and both anxiety and stress scores. 